\title{
TENSIONES Y CONFLICTOS ARMADOS EN EL SISTEMA MUNDIAL: UNA PERSPECTIVA GEOPOLÍTICA
}

\author{
Ricardo Méndez Gutiérrez del Valle \\ Instituto de Economía, Geografía y Demografía \\ Colegio Superior de Investigaciones Científicas (CSIC)
}

RESUMEN

El nuevo orden geopolítico mundial posterior al final de la Guerra Fría y que se corresponde con el actual proceso de globalización ha transformado la morfología, localización, causas y tipos de impactos generados por los conflictos armados, así como los discursos que en ocasiones pretenden justificarlos. A las guerras interestatales, ahora casi inexistentes, les sucede una violencia más difusa y un sentimiento de inseguridad bastante generalizado. Pero tanto las características internas y los actores presentes en los diferentes territorios que los padecen, como su inserción en las redes de flujos que se tejen en la actualidad, siguen siendo dimensiones importantes para su comprensión. El artículo resume las principales aportaciones recientes sobre estas cuestiones y revisa de forma crítica algunas ideas difundidas en estas dos últimas décadas. También propone un enfoque multicausal y multiescalar de los conflictos armados, destacando las aportaciones que pueden hacerse desde una perspectiva geopolítica.

Palabras clave: Geopolítica, conflictos armados, nuevas guerras.

\begin{abstract}
The new world geopolitical order following the end of the Cold War and which corresponds to the current process of globalization has transformed the morphology, location, causes and types of impacts caused by armed conflict, well at the discourses that sometimes seek to justify them. Interstate wars are now almost nonexistent and violence happens more diffuse, with a fairly widespread feeling of insecurity. But both the internal characteristics and the actors present in the different territories that suffer, as their inclusion in the networks of flows that are woven into the present, remain important dimensions for understanding. This paper summarizes the main recent contributions on these issues and critically reviews some ideas spread in the last two decades. It also proposes a multicausal and multi-scale approach of armed conflict, highlighting the contributions may be made from a geopolitical perspective.
\end{abstract}

Key words: Geopolitics, armed conflicts, new wars. 


\section{Introducción}

Hace aproximadamente dos décadas se inició la transición hacia una nueva etapa en la Historia de la humanidad que, sin duda, tiene precedentes en situaciones anteriores, pero también incorpora rasgos decididamente nuevos. La revolución de las tecnologías de información y comunicación, junto al posterior desarrollo de las redes digitales, sirvió como infraestructura para un proceso de globalización que ha densificado hasta límites antes desconocidos las redes de flujos materiales e inmateriales que atraviesan las fronteras interestatales. Ya se trate de mercancías, capitales, información, conocimiento o, en menor medida, personas, tiene lugar lo que Harvey (2003) calificó de compresión espacio-temporal, que favorece una creciente interacción entre los territorios y, como resultado de la competencia entre desiguales, acentúa todo tipo de contrastes, al tiempo que se incrementa el poder de aquellos grupos empresariales y financieros que controlan y dirigen esos flujos, en detrimento de los actores estatales.

En paralelo, el final del mundo supuestamente bipolar que trajo consigo la implosión de la Unión Soviética inició una evolución convulsa hacia un nuevo orden geopolítico en el sistema global que, no exento de ciertos rasgos caóticos, manifiesta ya unas características bastante bien definidas que hacen posible su interpretación (Méndez, 2011), más allá de las incertidumbres y nuevos riesgos que también le acompañan. En este escenario, la nueva fisonomía de la guerra, la multiplicación de actores implicados en la misma, el desplazamiento de las regiones más afectadas por la violencia armada, o la aparición de nuevas causas de conflicto bélico que se suman a otras de larga tradición justifican la necesaria renovación de una de las temáticas clásicas de los estudios geopolíticos.

A partir de ese contexto general de globalización, que aquí se da por sobreentendido, el artículo tiene como objetivo aportar una panorámica general sobre los conflictos bélicos en esta nueva etapa para perfilar sus rasgos básicos, los principales factores de esa sinrazón que es siempre la violencia armada y sus lógicas espaciales, como punto de partida en que poder situar el análisis monográfico de determinados conflictos. Esa pretensión generalizadora justifica la atención prioritaria que se presta a la interpretación teórica, con objeto de alimentar algunos de los debates abiertos en la bibliografía internacional reciente, con numerosas referencias a la misma que pueden permitir una profundización en las cuestiones abordadas.

De este modo, el primer epígrafe plantea de forma breve el significado de una geografía de los conflictos y justifica su presencia en los estudios geopolíticos, para centrar luego la atención en los profundos cambios acaecidos desde el final de la guerra fría, hasta el punto de dejar en cierto modo obsoleta la misma noción de guerra. El siguiente pretende esbozar el nuevo mapa de los conflictos armados en el mundo, el perfil difuso y discontinuo que revisten a menudo los frentes bélicos activos, o la necesidad de nuevos criterios para identificar el grado de inseguridad que padecen los territorios.

En la búsqueda de claves para poder comprender los conflictos de nuestro tiempo, el tercer epígrafe propone una interpretación multicausal y multiescalar de los mismos, mientras el siguiente resulta el más extenso al abordar una revisión crítica e individualizada de las principales causas que los originan. Frente a un debate reciente demasiado polarizado entre el choque de civilizaciones y los enfoques culturalistas, por un lado, frente a las guerras por los recursos y su mayor atención a las causas materiales, por otro, aquí se recuerda también la importancia de las raíces sociales y políticas subyacentes a muchos de esos enfrentamientos. El texto finaliza planteando la necesidad de una Geografía atenta a revelar las relaciones de poder que fundamentan y subyacen a las formas construidas. También a no olvidar la complementariedad de escalas y, en consecuencia, a aportar perspectivas 
globales para así comprender mejor buena parte de los principales problemas y retos a que se enfrentan nuestras sociedades en momentos críticos como el actual.

\section{La nueva morfología de los conflictos bélicos}

Toda sociedad genera contradicciones y enfrentamientos, tanto en su interior como con otras, surgidos cuando dos o más individuos, grupos u organizaciones persiguen similares objetivos, incompatibles entre sí o que, al menos, se perciben como tales. En palabras de Stéphane y Yann (2011: 3), los conflictos surgen «de la rugosidad de esas relaciones» y, en tal sentido, «toda relación entre actores o estructuras puede situarse en un gradiente que va del acuerdo al conflicto». En esa escala, la incapacidad para encontrar soluciones negociadas ante posiciones opuestas y el desencadenamiento de diversas formas de violencia física supone la situación de mayor gravedad, con ámbitos espaciales y temporales de incidencia muy heterogéneos.

La Geografía se encuentra implicada de forma directa en la cuestión de los conflictos, al menos desde tres perspectivas complementarias. Por un lado, son numerosos a lo largo de la Historia aquellos cuyo origen se sitúa en la conquista y apropiación de territorios, el control de determinados recursos estratégicos (agua, alimentos, minerales...), o la imposición de unos determinados usos del suelo frente a otros alternativos. Al mismo tiempo, el mapa de los conflictos pone de manifiesto la existencia de ciertas lógicas espaciales y pautas de distribución que se relacionan con las características internas de los territorios (económicas, sociales, políticas, culturales...), sus herencias o el interés que despiertan y la consiguiente intervención - directa o indirecta - de actores externos. Por último, cuando los conflictos alcanzan cierta gravedad y permanencia generan un impacto muy negativo, tanto sobre la población como sobre la capacidad de desarrollo de las áreas afectadas, convirtiéndose en importante factor explicativo de sus dinámicas territoriales. De ahí que la geografía de los conflictos - activos o larvados, violentos o negociados - constituya una temática de carácter transversal y de interés creciente, orientada a interpretar sus causas, identificar sus consecuencias y proponer alternativas de solución.

Si, más allá de las múltiples definiciones existentes en el siglo transcurrido desde su aparición, se entiende la geopolítica como el estudio de las relaciones y estrategias de poder que establecen diferentes actores - tanto estatales como no estatales - y que tienen implicaciones espaciales, parece justificado su persistente interés por los conflictos, en especial los de carácter armado (Losano, 2011). Resulte o no exagerada la afirmación de que «la historia de los asuntos internacionales en los últimos cinco siglos ha sido con frecuencia una historia de guerra o, al menos, de preparación para la guerra» (Kennedy, 1988: 654), sus negativos efectos sobre el pasado y el presente de numerosos territorios justifican una línea de investigación netamente transdisciplinar, con una preocupación específica por conocer y comprender su dimensión espacial, lo que va más allá de su simple localización sobre un mapa. Esto también puede suponer una aportación útil a la llamada investigación para la paz (Galtung, 1996), al incorporar claves interpretativas que favorezcan estrategias más eficaces para la superación de los conflictos.

Durante buena parte del siglo XX la atención se focalizó en los conflictos interestatales cuya máxima expresión fueron las sucesivas guerras hegemónicas entre grandes potencias, que alcanzaron una dimensión mundial, quedando en un segundo plano otras de ámbito regional o local, más numerosas y con participación de diferentes grupos armados además de los ejércitos estatales. Pero, con el inicio de la posguerra fría hace ahora dos décadas, tanto las características como las principales causas, localización o efectos de los conflictos armados han conocido una evidente transformación, sobre la que abundan los diagnósticos 
realizados en los últimos años (Harbom y Wallensteen, 2005; Hobsbawm, 2007; Gregory, 2010; Megoran, 2011). Sin pretender ahora una panorámica de conjunto de estas nuevas guerras (Kaldor, 1999), sí merece la pena detenerse en algunos debates recientes sobre sus rasgos identitarios y las raíces que los alimentan.

Tal vez el primer aspecto a destacar de esta nueva morfología de la violencia armada que Beck calificó como postnacional es su perfil difuso, por cuanto «la distinción entre guerra y paz es espacial y temporalmente eliminada» (Beck, 2005: 18). La ausencia de declaración del inicio o final de los enfrentamientos conlleva la persistencia de numerosos conflictos de baja intensidad, con frecuencia intermitentes durante largos periodos y sin frentes de combate definidos, lo que extiende sus efectos sobre territorios discontinuos, que a menudo atraviesan unas fronteras interestatales porosas, convirtiendo a la población civil en su principal víctima y a los flujos de refugiados o desplazados en consecuencia frecuente. Esos contornos imprecisos de lo que algunos autores califican como pequeñas guerras, reflejo de una violencia más decentralizada y segmentada que en el pasado, afectan la propia fiabilidad de las estadísticas sobre conflictos que hoy elaboran diversas instituciones con difusión internacional (Stockolm International Peace Research Institute, Heidelberg Institute for International Conflict Research, Department of Peace and Conflict Research University of Uppsala, Event Data Project on Conflict and Security Free University of Berlin...) y que utilizan criterios diversos para definir la guerra según el número mínimo de muertes anuales, al tiempo que realizan estimaciones no coincidentes sobre víctimas civiles.

No obstante, lo que sí parece suficientemente comprobado es que, en el secular combate entre guerra y paz, el final del enfrentamiento bipolar y el proceso de globalización no trajeron consigo un mundo más estable sino que, por el contrario, la conflictividad alcanzó un momento álgido en la última década del pasado siglo y aún se mantiene en niveles bastante superiores a los existentes hace cuatro o cinco décadas. Así, por ejemplo, según los datos

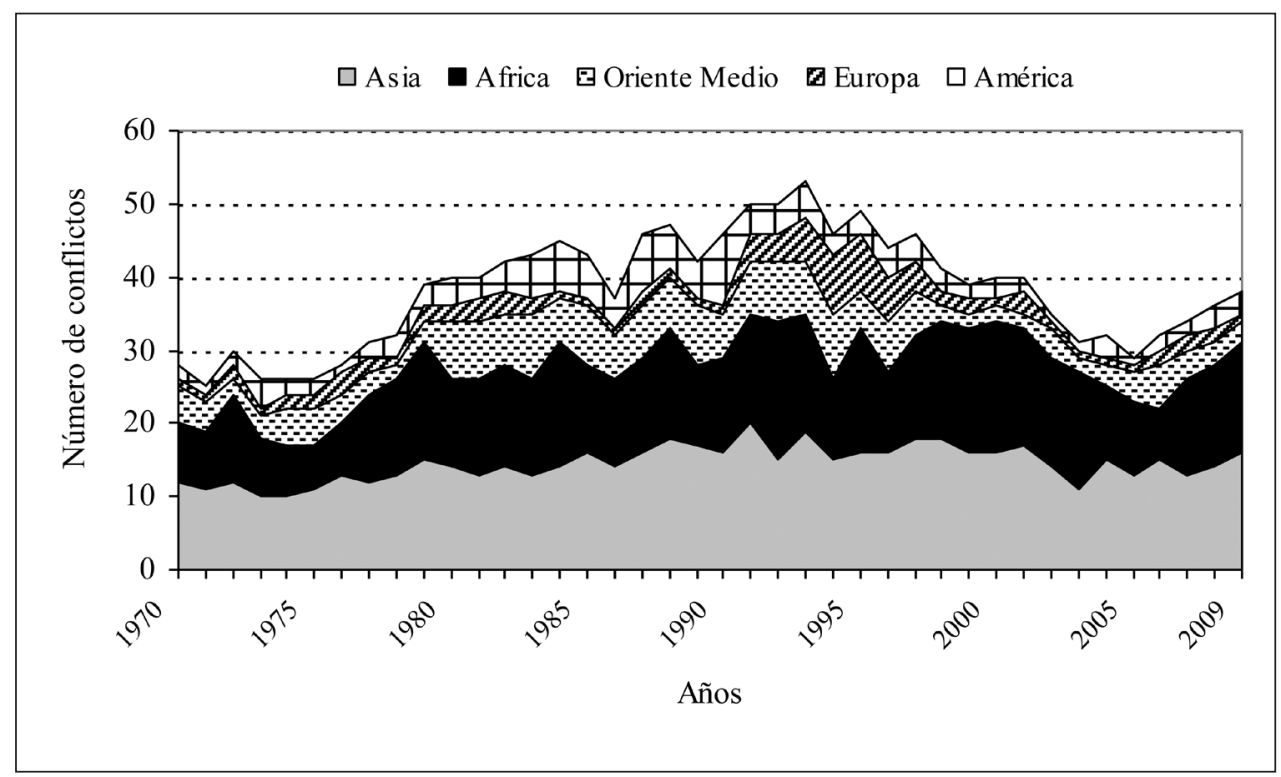

Figura 1. Evolución del número de conflictos armados en el mundo, 1970-2009.

Fuente: Adaptado de Uppsala Conflict Data Program. 
del Uppsala Conflict Data Program, que consideran conflicto armado a todo aquel que superó las 25 víctimas mortales por año (figura 1), mientras en 1970 sólo se registraron 28 conflictos activos en el mundo, esa cifra aumentó a 46 en 1990, alcanzando sus niveles máximos en los años de transición que siguieron a la desaparición de la Unión Soviética (hasta 53 en 1993). Pero, lejos de tratarse de un momento excepcional, reflejo de la ruptura del orden establecido, en la primera década de nuestro siglo el número de conflictos sólo se reduce con lentitud y si eran 41 en el año 2000, aún son 38 en 2009. Las víctimas mortales provocadas se sitúan en unos 15 millones, lo que equivale a las estimadas en la primera guerra mundial y a una cuarta parte de las producidas en la segunda, reflejo asímismo de este nuevo perfil. Lo que no ha cambiado de forma significativa en estos años es su concentración en Asia y África, donde ya se localizaban el 71,4\% del total en 1970, el 66,0\% en 1993 (por el aumento de la conflictividad en los Balcanes) y hasta el 81,6\% en 2009.

Puede constatarse también que la mayor conflictividad en las dos décadas posteriores a 1991 respecto a las dos precedentes coincide con una evolución casi idéntica del volumen de refugiados (figura 2). Definidos como aquellos que se ven forzados a abandonar su país por un conflicto bélico o por ser perseguidos debido a su raza, religión, nacionalidad, pertenencia a un grupo social u opinión política, los atendidos por el Alto Comisionado de Naciones Unidas para los Refugiados (ACNUR o UNHCR) apenas alcanzaban los dos millones y medio en 1970 (a los que se añadían los palestinos atendidos por la UNRWA, creada en 1949). Esa cifra se triplicó con creces en la década de los setenta (8,9 millones en 1980) y volvió a duplicarse en los años siguientes, con su máximo en 1992 (18,3 millones), al sumarse los refugiados que provocaron los conflictos en Latinoamérica (Colombia, El Salvador, Nicaragua), Oriente Medio (guerras Irán-Irak y Afganistán) o Grandes Lagos africanos, entre otros.

Pese a su lenta y discontinua reducción posterior, en 2010 aún se contabilizan diez millones de refugiados, a los que se suman otros 26 de desplazados dentro de las fronteras de su propio país. De este modo, ambos se convierten también en seña de identidad de nuestro tiempo, que condena a esta población especialmente vulnerable a vivir ajena al

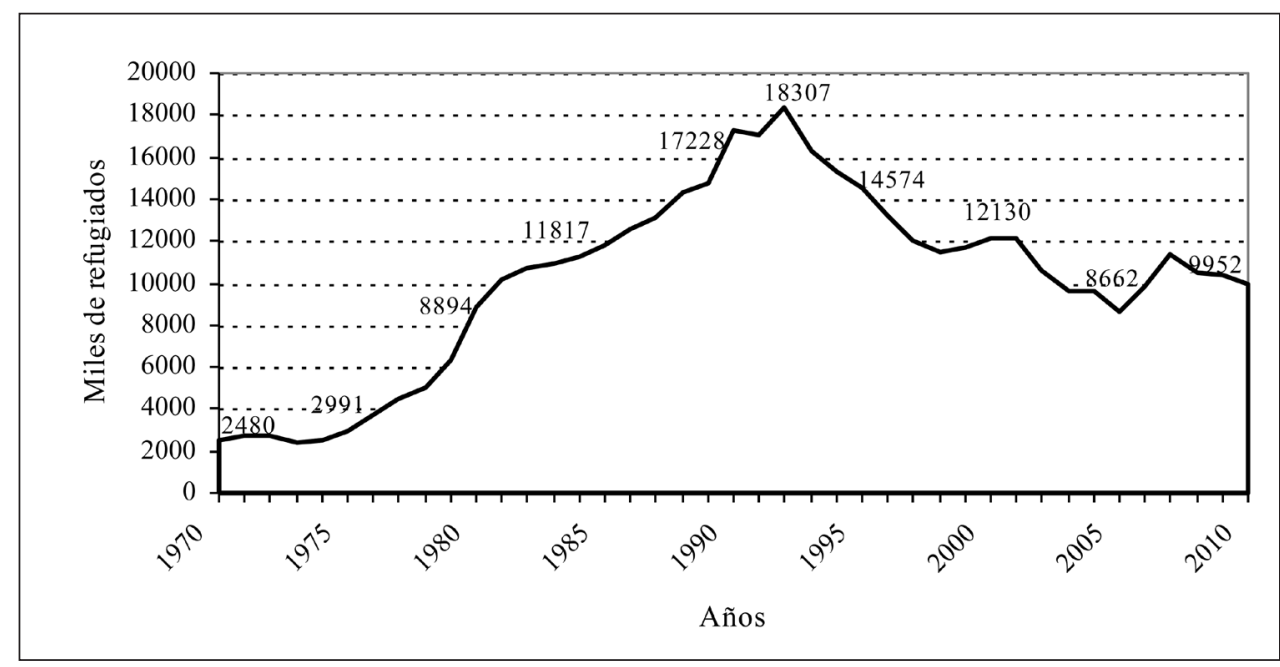

Figura 2. Evolución del número de refugiados en el mundo, 1970-2010

Fuente: ACNUR. 
territorio en que reside durante largos periodos, a menudo confinada en campos aislados, sin trabajo o inmersa en el submundo de la economía ilegal y dependiente de una ayuda exterior gestionada por organizaciones que forman parte de un gobierno humanitario al que son con frecuencia ajenos (Agier, 2007). Desprovistos, por tanto, de cualquier derecho de ciudadanía y en una permanente provisionalidad y situación de riesgo, sin un sentido ni un lugar para desarrollar su vida, se convierten en daño colateral de esos conflictos bélicos y a menudo presa fácil para su reclutamiento por diversos tipos de movimientos radicales que crecen en ambientes dominados por la desesperación y la falta de horizontes de futuro.

Junto a lo anterior, asistimos también a la «radical transformación de una de las tradicionales funciones y atribuciones del Estado-nación moderno: la guerra» (Romero y Nogué, 2007: 115). Esa pérdida del monopolio de la violencia legal, que multiplica el número de actores implicados de forma directa en los conflictos, ofrece, al menos, dos manifestaciones complementarias.

La primera y más evidente supone que, junto a los ejércitos regulares de los Estados, en la mayoría de acciones participan grupos armados irregulares de muy diverso signo, que incluyen desde guerrillas a contingentes paramilitares financiados por señores de la guerra, redes mafiosas vinculadas al crimen organizado y grupos calificados de terroristas por el tipo de estrategia que aplican, financiados en bastantes ocasiones mediante diversas formas de economía ilegal. Su confrontación con fuerzas armadas estatales da origen a las llamadas guerras asimétricas que, desde Colombia a la cuenca del Congo, el Sahel, Chechenia, Afganistán, Pakistán, Birmania, Indonesia, Filipinas y otros países del Sur, salpican hoy un mapa que tiende con frecuencia a enquistarse al no abordarse una solución efectiva a las razones que las originaron. Mientras los ejércitos de las grandes potencias intentan limitar sus operaciones sobre el terreno en beneficio de una guerra tecnológica basada en bombardeos aéreos de precisión o lanzamiento de misiles sobre objetivos estratégicos, el hecho de que más del $60 \%$ de las víctimas lo sean por armas ligeras compradas en el mercado negro (Naylor, 2005) nos recuerda el lado más oscuro de esta nueva morfología bélica.

Pero, junto a la expansión de los conflictos informales, la lógica de la globalización neoliberal también se manifiesta en una creciente privatización de la guerra. Se ha multiplicado así la externalización de tareas por parte de los ejércitos de numerosos países - en especial Estados Unidos - a favor de compañías privadas, fundadas y dirigidas en muchos casos por antiguos militares y agentes de los servicios de seguridad, que actúan como tropas mercenarias y participan también en actividades complementarias: logística y transporte de tropas o material, seguridad de personas o recintos, construcción de acuartelamientos, cárceles e infraestructuras, etc. Grupos empresariales como Dyncorp International (integrada en el consorcio Computer Sciences Corporation), Kellogg Brown\&Root (integrada en Halliburton), o Military Professional Ressource Incorporated (en L-3 Communications) son algunos de los principales dentro de una intrincada red en la que se integran varios cientos de firmas.

Estos guerreros corporativos (Singer, 2003), para los que el negocio de la guerra constituye la base de su actividad, vieron ampliado su mercado con la administración BushCheney, convirtiendo Irak y Afganistán en su principal campo de operaciones y fuente de beneficios. Pero su presencia se ha convertido en ingrediente habitual que no sustituye al Estado - fuente de financiación y cliente preferente - sino que desdibuja sus límites y favorece formas de gestión público-privada de la guerra. Lo que, en términos menos convencionales, significa que su presencia resulta útil cuando se quiere reducir las bajas oficiales en conflictos impopulares, realizar operaciones de guerra sucia, reducir costes o aumentar la seguridad de gobernantes y yacimientos estratégicos mediante la presencia de cuerpos de élite que cubren las deficiencias del ejército regular en Estados frágiles. 


\section{Mapa de conflictos e índice global de paz: dos perspectivas complementarias}

Durante las más de cuatro décadas en que la política internacional estuvo dominada por el enfrentamiento entre dos bloques antagónicos, la distribución de los conflictos armados mantuvo pautas bien definidas que facilitaban su interpretación. Por un lado se situaron aquellos ligados de forma directa a la pugna por la hegemonía, que se concentraron en la margen exterior de Eurasia, dentro de lo que Spykman denominó el Rimland, donde la tensión por expandir sus respectivas áreas de influencia se unió a causas locales para desencadenar guerras de especial intensidad como las producidas en Corea, Vietnam, Laos, Camboya, Afganistán o las árabe-israelíes. Un segundo grupo de conflictos correspondieron a los derivados de la lucha por la independencia de las metrópolis, sobre todo en África (Argelia, Angola, Mozambique...), o bien al enfrentamiento entre los nuevos Estados postcoloniales por afirmar su posición regional (India-Pakistán, Irán-Irak...). Junto con ellos, un último tipo que tendió a aumentar con el paso del tiempo fueron las guerras civiles en el interior de un número creciente de Estados del Tercer Mundo, donde factores sociales, ideológicos o religiosos generaron la aparición de movimientos guerrilleros opuestos a los gobiernos establecidos (desde China a Cuba, Bolivia, El Salvador, Nicaragua, Congo, Nigeria...), aunque a menudo fueran interpretados dentro de la lógica bipolar.

El mapa de conflictos propio de la postguerra fría muestra una mayor dispersión que es coherente con ese carácter más difuso ya señalado, con alrededor de una treintena de países que en estos últimos años superaron las 20.000 víctimas mortales. Junto con esto, el segundo rasgo a destacar es su cada vez mayor concentración en las regiones pobres del mundo, principalmente de Asia y África, que aumentan su participación relativa tras el final de los conflictos producidos durante los años ochenta y noventa del siglo XX en Centroamérica o los Balcanes. No obstante, una mirada más atenta permite identificar dos ámbitos principales donde la violencia armada ha generado sus más graves manifestaciones (figura 3).

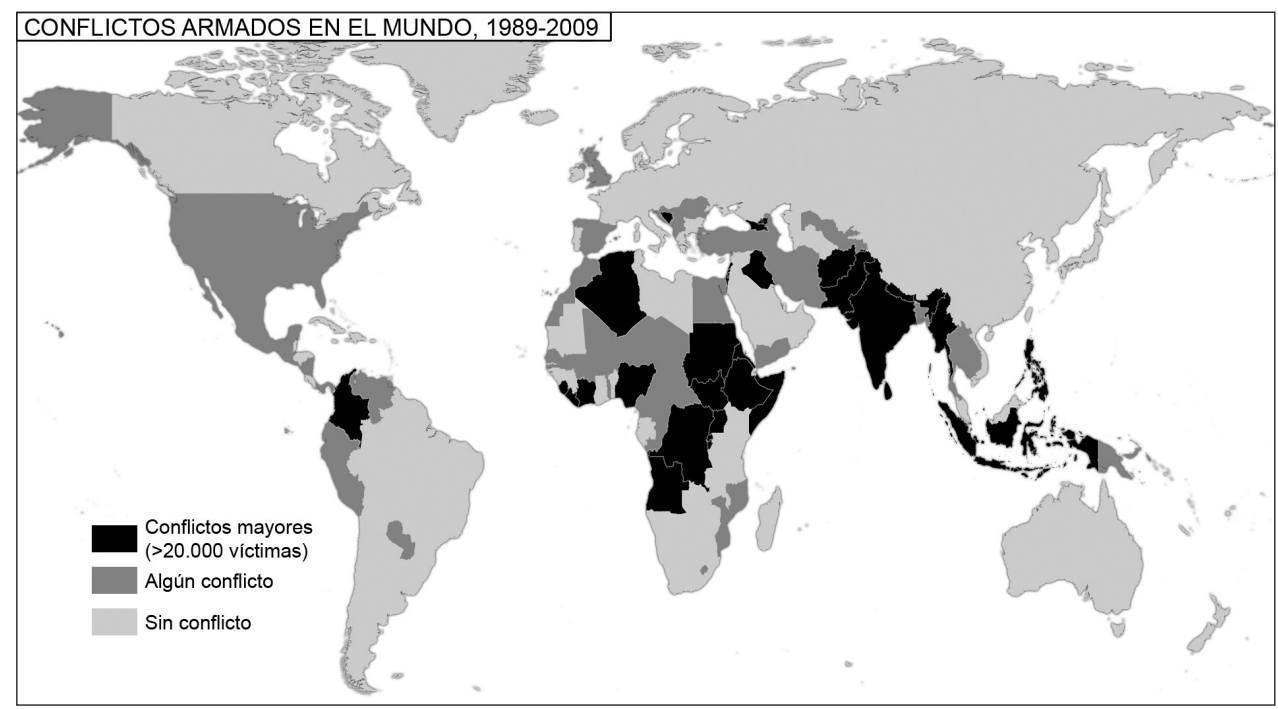

Figura 3. Mapa de conflictos armados en el mundo, 1989-2009. 
En primer lugar, se dibuja con nitidez un eje de conflictos dispuesto de oeste a este, que comienza en los Balcanes, continúa por el Cáucaso, Oriente Próximo y el Kurdistán, para adentrarse y alcanzar su mayor intensidad en Oriente Medio y Asia Central (Irak, Afganistán, Tayikistán...), continuando por Asia meridional (Pakistán, Cachemira, Sri Lanka), hasta llegar al extremo sureste del continente (Birmania, Aceh, Filipinas). Aunque su carácter de zona de contacto entre la civilización islámica y otras fue un aspecto que centró la atención de determinados autores, cualquier acercamiento superficial a enfrentamientos tan numerosos y heterogéneos pone en evidencia la existencia de raíces muy diversas, que hacen entrar en juego otros factores explicativos considerados en páginas posteriores.

En el continente africano puede observarse, por su parte, un doble eje de conflictos que converge en su extremo nororiental, el denominado Cuerno de África (Somalia, Eritrea, Etiopía). Desde ese vértice, las áreas asociadas a mayores niveles de violencia penetran, por una parte, en sus regiones centrales (Ruanda, Burundi, Uganda, República Democrática del Congo) hasta llegar a la costa atlántica (Angola), mientras un segundo eje atraviesa algunos de los países del Sahel más pobres del globo (Sudán, Chad, Níger, Mali), alcanzando también el litoral en Argelia, Sahara occidental y Mauritania, así como en África occidental (Liberia, Sierra Leona, Nigeria). Por comparación, los restantes focos de violencia externos a estas áreas, asociados a la persistencia de movimientos guerrilleros y mafias de narcotraficantes en algunos países de Latinoamérica (México, Colombia), o a ciertos grupos independentistas radicales en Europa, muestran una importancia muy limitada.

Pero si los territorios y las sociedades más conflictivos se identifican, también en este periodo, con ciertas regiones del planeta, en los restantes la ausencia de guerra no siempre equivale a paz, que es un concepto más complejo que incluye diferentes aspectos. En el intento de comparar la situación de los países del mundo a este respecto destaca el interés suscitado por el índice global de paz, un indicador sintético que desde 2007 publica el Institute for Economics and Peace, organización privada dedicada a la enseñanza y la investigación sobre paz y desarrollo. En su quinto informe publicado en 2011 incluye ya a 153 países, clasificados a partir de 24 indicadores cuantitativos y cualitativos, obtenidos estos últimos a partir de las respuestas de un panel de expertos, mediante su conversión en valores estandarizados (valores 1 a 5). Esos indicadores hacen referencia a la conflictividad interna y externa de cada Estado (número de guerras libradas, víctimas, relación con Estados limítrofes, número de desplazados...), la libertad, seguridad y respeto a los derechos humanos de que disfrutan sus ciudadanos (inestabilidad política, situación de los derechos humanos, posibilidad de actos terroristas, nivel de criminalidad y homicios, población reclusa...), así como su grado de militarización (efectivos del ejército y cuerpos de seguridad, gasto militar sobre PIB, compra o venta de armas...). Al clasificar a los diferentes países por su índice promedio se obtiene una imagen complementaria que la derivada de localizar tan sólo los conflictos armados, pues si bien ambos mapas son el negativo uno del otro, aparecen situaciones no previstas en la perspectiva anterior que dotan de mayor complejidad al diagnóstico (tabla 1).

Así, tal como cabría esperar, países como Somalia, Irak, Sudán, Afganistán o la República Democrática del Congo ocupan algunos de los últimos lugares de la tabla, reflejo de su situación actual de extrema violencia, inseguridad para sus ciudadanos e inestabilidad política. Pero en este grupo también aparecen otros como Corea del Norte (por el militarismo y escaso respeto a los derechos humanos), Israel (por el prolongado conflicto palestino), Rusia (por los del Cáucaso norte), o Pakistán (por la violencia en Baluchistán o la presencia de AlQaeda), menos visibles en otro tipo de análisis. En el extremo opuesto, algunos países del mundo desarrollado como Islandia, Nueva Zelanda, Japón, Dinamarca, Austria, Canadá o República Checa ocupan los primeros lugares, mientras otros países 
Tabla 1

ÍNDICE GLOBAL DE PAZ, 2011: PAÍSES EN LAS PRIMERAS Y ÚLTIMAS POSICIONES

\begin{tabular}{|c|l|c|l|}
\hline Puesto & \multicolumn{1}{|c|}{ País } & Puesto & \multicolumn{1}{c|}{ País } \\
\hline 1 & Islandia & 153 & Somalia \\
2 & Nueva Zelanda & 152 & Irak \\
3 & Japón & 151 & Sudán \\
4 & Dinamarca & 150 & Afganistán \\
5 & República Checa & 149 & Corea del Norte \\
6 & Austria & 148 & República Democrática Congo \\
7 & Finlandia & 147 & Rusia \\
8 & Canadá & 146 & Pakistán \\
9 & Noruega & 145 & Israel \\
10 & Eslovenia & 144 & República Centroafricana \\
\hline
\end{tabular}

Fuente: Global Peace Index (disponible en: http://www.visionofhumanity.org/gpi-data/\#/2011/scor)

nórdicos como Suecia o Noruega retroceden posiciones ante la expansión de la violencia de ultraderecha. En ese ranking, España ocupa el puesto $28^{\circ}$, muy por delante de Estados Unidos, que tan sólo aparece en el lugar $82^{\circ}$.

\section{Etiología de la guerra: una perspectiva multiescalar y multicausal de los conflictos armados}

Pero si el perfil de los conflictos armados o su distribución geográfica han cambiado, también parecen haberlo hecho las principales causas que los provocan. Más allá de la especificidad de cada caso, tan sólo un enfoque multiescalar y multicausal puede ofrecer una comprensión suficiente de las mismas (Méndez, 2011: 245).

Finalizada la confrontación ideológica que durante la guerra fría sirvió para justificar los numerosos enfrentamientos bélicos del periodo y ocultar a menudo las claves locales que los engendraban, el panorama actual resulta más confuso y ha alimentado numerosos debates recientes que resultan en ocasiones demasiado localistas, al centrar su atención en los factores internos e ignorar la frecuente influencia externa y su relación con las dinámicas globales del poder. El orden geopolítico característico de cada periodo histórico define unos actores dominantes, un contexto de relaciones y un marco institucional que afectan no sólo la intensidad y forma de los conflictos, sino también su desigual localización y el valor geoestratégico de los diferentes territorios en función de criterios que son cambiantes en el tiempo. Sin negar que las claves internas son siempre importantes en la explicación de cada conflicto, la inserción de esa perspectiva local en su contexto regional y en el actual escenario global donde cobran mayor fuerza actores con influencia transfronteriza permite ofrecer una perspectiva más adecuada que la atención exclusiva a cualquiera de esas escalas.

Por otra parte, frente a la atractiva simplicidad de las interpretaciones monocausales y el éxito mediático que ha acompañado a algunas de ellas, ya se trate de las guerras por el petróleo o del choque de civilizaciones, la realidad de los conflictos es habitualmente compleja, exigiendo integrar y jerarquizar en cada caso la influencia de factores diversos, a menudo interdependientes. La violencia de raíz étnica o cultural despertó particular aten- 
ción en los primeros años de posguerra fría, al considerar que los sentimientos de agresión identitaria estaban en la base de numerosos conflictos locales. No obstante, una mirada más atenta permite apreciar que, incluso en estos casos, con frecuencia tales reivindicaciones son la parte visible de un problema más profundo, con raíces en la pobreza y las desigualdades sociales, las ambiciones políticas, la crisis de ciertos Estados o el control de territorios y recursos materiales valiosos, aspectos todos ellos que exigen un comentario individualizado.

\subsection{Factores culturales y guerras identitarias}

Desde el nacimiento de los Estados modernos, la mayor parte de las guerras, sobre todo las principales, tuvo su fundamento en la ambición de conquistar y ocupar territorios, explotar sus recursos y modificar sus fronteras. Pese a que las guerras de conquista parecen hoy excluidas por la comunidad internacional, eso no significa que las rivalidades territoriales y el cuestionamiento de las fronteras heredadas hayan perdido su importancia como factor de conflicto, sobre todo allí donde diversos tipos de nacionalismos e irredentismos siguen reivindicando una alteración del mapa político como respuesta a demandas identitarias nunca satisfechas (Nogué y Vicente, 2001). En tal sentido, durante las dos últimas décadas, la implosión de la Unión Soviética y algunos otros Estados multiculturales, o la imprecisión de algunas fronteras postcoloniales, fueron origen de tensiones saldadas, según los casos, con guerras civiles, contiendas transfronterizas o nacimiento de nuevos Estados, de los que Timor Oriental, Montenegro y Sudán del Sur resultan, por el momento, sus últimos ejemplos.

En esta línea argumental ha alcanzado notable difusión la referencia a las diferencias étnicas y, sobre todo, culturales (religiosas, lingüísticas...) como factor destacado de fractura geopolítica, con la conocida tesis del choque de civilizaciones como su exponente más acabado aunque no único (Huntington, 1997). La explicación de los conflictos armados que ofrecen las tesis culturalistas identifica el rebrote de los sentimientos identitarios en muchos lugares del mundo, instrumentalizados luego por determinados partidos o movimientos, como reacción defensiva frente a las amenazas de una globalización homogeneizadora y violentamente competitiva, generadora de crecientes contrastes entre sociedades y en el seno de las mismas. También como reflejo de la crisis del Estado frente a los nuevos poderes globales y la erosión sufrida por las fuentes tradicionales de legitimidad política.

La búsqueda de la afinidad étnica o cultural como factor de cohesión interna y de culpabilización del otro tiene raíces psicosociales profundas y a menudo se entremezcla con herencias de un pasado en que los agravios acumulados - reales o imaginados - mantienen en bastantes ocasiones su capacidad movilizadora y pueden alimentar en casos extremos una respuesta violenta que Maalouf (1998) vinculó con la existencia de identidades asesinas. En tal sentido, los particularismos fueron utilizados, en ocasiones, «para justificar políticas autoritarias, para crear chivos expiatorios, para movilizar el apoyo basándose en el miedo y la inseguridad» (Kaldor, 2001: 107).

Así, el supuesto retorno de las guerras de religión, interpretadas como reflejo de una incompatibilidad entre credos, valores y modos de vida capaz de desatar la violencia, llevó hasta la delimitación por Huntington de líneas de fractura entre civilizaciones que se identificaban, sobre todo, por esa característica. El protagonismo otorgado a las que denominó como sangrientas fronteras del Islam le permitió agrupar bajo un denominador común conflictos tan heterogéneos como los de Bosnia-Herzegovina, Kosovo, Chechenia, Palestina, Líbano, Nagorno-Karabaj, sur de Sudán, Nigeria, Cachemira, Aceh o sur de Filipinas, entre otros. La expansión del islamismo radical y la inclusión de numerosos grupos de este signo en la lista elaborada por el Departamento de Estado norteamericano, reflejo de la declaración de una guerra contra el terror tras los atentados del 11-S, no hicieron 
sino reforzar la difusión de unas ideas cuyo simplismo encontró acogida en ciertos medios de comunicación.

Son muchas las críticas realizadas en la última década a este tipo de argumentos y, en especial a las tesis de Huntington (Russett, O’Neal y Cox, 2000; Fox, 2005). Estas incluyen desde el rechazo a la supuesta homogeneidad interna de tales civilizaciones al de una teoría del conflicto basada en un determinismo cultural que ignora las bases materiales y sociopolíticas de muchos de ellos, o la experiencia de una secular convivencia intercultural pacífica en la mayor parte del mundo. No obstante, su arraigo en parte de la opinión pública convierte este tipo de argumentos en bandera agitada aún con demasiada frecuencia por determinados grupos para defender su acceso al poder ocultando otro tipo de razones e intereses también presentes. Tal como afirma Prat (2010: 18-19), «el fanatismo religioso o el nacionalismo excluyente pueden ser una causa de las guerras. Pero conviene aclarar que la existencia de diferencias nacionales, étnicas o religiosas no tiene por qué conducir forzosamente al enfrentamiento violento. En cambio, la manipulación política e ideológica de estas diferencias sí que puede provocar el conflicto y la guerra».

\subsection{Alimentos, agua y energía: la pugna por los recursos estratégicos}

En su informe anual sobre riesgos globales correspondiente a 2011, el influyente Foro Económico Mundial identifica entre los más importantes la seguridad alimentaria, hídrica y energética. El previsible aumento de su demanda en las dos próximas décadas, que cifra en un $30-50 \%$, junto a la creciente volatilidad de sus precios, puede suponer impactos negativos sobre la sostenibilidad ambiental y promover una creciente inestabilidad geopolítica que debería promover soluciones compartidas entre los múltiples actores implicados (World Economic Forum, 2011: 27-33). Pero reconocer esas previsibles tensiones derivadas de un modelo ya insostenible a medio plazo no debe hacer olvidar el hecho de que el acceso a estos recursos es ya motivo de conflicto en diferentes regiones del mundo, cuestión sobre la que esta institución no se pronuncia.

El grave problema de la inseguridad alimentaria es, sin duda, un asunto que nada tiene de actual y hace ya seis décadas, en su Geopolítica del hambre, Josué de Castro (1951) llamó la atención sobre su gravedad. Pero si la inseguridad alimentaria se resiste a desaparecer desde entonces, las tendencias recientes parecen incluso agravar la situación desafiando las expectativas de quienes pusieron en el desarrollo tecnológico ligado a la revolución verde y en la liberalización de los mercados su esperanza para lograrlo. Así, según el último informe de la FAO, entre 2007 y 2009 el aumento de precios de los alimentos y, más tarde, la recesión económica internacional provocaron un incremento de las personas subalimentadas hasta alcanzar los 1.023 millones, el $18 \%$ de la población total de los países que se continúan calificando de forma discutible como en desarrollo, con un 62\% del total en Asia y otro $26 \%$ en África subsahariana, en donde afecta a uno de cada tres habitantes (FAO, 2011).

Esa cifra sin precedentes desde que existen estadísticas internacionales no es fruto de una coyuntura desfavorable de malas cosechas, sino que son varios los factores que nos alejan de alcanzar uno de los Objetivos del Milenio enunciados por Naciones Unidas, consistente en reducir esa vergonzosa cifra al $10 \%$ en 2015 . La elevación de la demanda de productos básicos (cereales, oleaginosas, lácteos, carnes, azúcar) por el aumento del nivel de consumo en países emergentes, su conversión en productos sometidos también a la especulación de los mercados, o su utilización para biocombustibles, tiende a elevar los precios y con ello dificulta su importación por países con escasos recursos y su adquisición por los grupos de población más pobres. Al mismo tiempo, el desarrollo de la agricultura monoespecializada de exportación con objeto de obtener divisas y, con ello, solvencia financiera, condujo a 
muchos de esos países a postergar la producción destinada a la subsistencia de su población, lo que la hace ahora más dependiente de unas oscilaciones de precios ajenas a su control y aumenta su vulnerabilidad (Benhammou, 2009).

En suma, aunque es más habitual considerar el efecto nocivo de las guerras sobre la producción agraria en los territorios afectados, resulta evidente que la inseguridad alimentaria actual en amplias regiones del mundo se convierte en un factor de tensión social e inestabilidad política que va mucho más allá del efecto provocado por hambrunas puntuales y del recurso a la ayuda humanitaria frente a tales emergencias. De nuevo en este caso, la exigencia de mayor regulación internacional no es una respuesta suficiente, pero sí necesaria tal como también ocurre en el caso del agua.

La referencia a la hidropolítica, definida como «la política hecha con el agua, mediante la cual los gobiernos nacionales buscan afirmar su hegemonía dentro de una región» (Fantini, 2003: 435), nos recuerda la influencia que este recurso estratégico tiene como factor potencial de conflicto. Sobre todo, allí donde la limitada oferta disponible, el rápido aumento de su demanda o su privatización acentúa la pugna por su control. Más allá de estos focos de tensión localizados, debe recordarse que la población del mundo desarrollado, estimada en un $12 \%$ del total, consume en torno al $80 \%$ del agua potable en tanto unos 1.500 millones de personas no disponen de acceso directo a ella según Naciones Unidas, lo que constituye otro exponente de esa violencia estructural ya mencionada.

Las guerras por el agua, concentradas sobre todo en la diagonal árida del mundo, entre el Sahel y Asia Central, allí donde el estrés hídrico la convierte en recurso escaso y a menudo sobreexplotado, tienen su reflejo a diferentes escalas e implican a actores muy diversos (Shiva, 2002). Es fuente de litigios entre Estados que se disputan el control de grandes ríos, desde el Indo al Nilo, el Tigris, el Eúfrates o el Paraná, entre otros muchos. Está en la base de enfrentamientos entre comunidades que ocupan un territorio, como el que explica la ocupación de los Altos del Golán y la progresiva colonización de Cisjordania por Israel para asegurarse el control de la cabecera del río Jordán y de los principales acuíferos subterráneos de la región, en contra de sus habitantes palestinos o de los intereses de Siria y Líbano. Pero la conflictividad asociada al agua se multiplicó y dispersó territorialmente en las dos últimas décadas como resultado de la difusión de políticas neoliberales impuestas por el Fondo Monetario Internacional y el Banco Mundial a los países deudores y la consiguiente privatización de servicios públicos, incluida en algunos casos la venta o concesión a grandes transnacionales (Bechtel, Suez, Vivendi, Thames Water...) del suministro de agua, que en casos como el boliviano o el argentino derivaron en revueltas populares por su encarecimiento y el deterioro de la red ante la falta de reinversión.

No obstante, la energía es probablemente el sector en donde las cuestiones geopolíticas resultan hoy más visibles y con incidencia global, al menos desde tres puntos de vista: (i) asegurar el abastecimiento energético frente a una demanda mundial creciente se ha convertido en factor de seguridad para todos los Estados; (ii) controlar los recursos y su transporte afecta la posición de las grandes potencias y el poder de los grupos empresariales implicados; (iii) avanzar hacia un nuevo modelo energético más sostenible es responsabilidad de una sociedad internacional que también en este ámbito muestra sus muchas debilidades.

Tanto el crecimiento de la población y la capacidad productiva, como de la movilidad y los niveles de consumo, han elevado con rapidez una demanda de energía primaria que sigue dependiendo en gran medida de fuentes no renovables como los hidrocarburos $(59 \%$ del total) y el carbón (29\%), generadores también de elevadas emisiones a la atmósfera que se vinculan al cambio climático. Según las previsiones de la Agencia Internacional de la Energía, en 2030 se duplicará el consumo energético de 1990 y se prevé que los hidrocarburos aún representen el 60\% del total (EIA, 2009), cifra que puede revisarse al alza 
tras el aumento de las reticencias provocadas por la energía nuclear tras el accidente de la central de Fukushima. La insostenibilidad del modelo energético actual a medio plazo y la perspectiva de un progresivo encarecimiento para estos recursos suponen así una amenaza global que se hace más patente con el paso de los años. Pero cuando se territorializa la situación actual es cuando adquiere dimensiones geopolíticas evidentes.

El reducido club de potencias altamente consumidoras de energía se ha visto ampliado con la incorporación de países emergentes como India, Brasil y, sobre todo, China, cuyas altas tasas de crecimiento en las dos últimas décadas las sitúan ya en los primeros lugares, al tiempo que las hace cada vez más dependientes de recursos procedentes del exterior de sus fronteras. Aumentan también, en consecuencia, las tensiones por ampliar y consolidar sus respectivas áreas de influencia con relación a las principales regiones productoras mediante acuerdos de colaboración interestatales y la firma de contratos entre grandes empresas de los países implicados, que alcanzan su mejor exponente en el caso de los hidrocarburos y, en especial, del petróleo.

Se trata de un recurso estratégico por ahora irremplazable, con el que «se compran y se venden la seguridad económica y militar, el crecimiento industrial, los medios para desplazarse, las posibilidades de desarrollo» (Huillier, 2003: 6). Su historia durante la segunda mitad del siglo XX es fundamental para comprender la convulsa trayectoria de áreas como Oriente Medio, que aún es la principal región productora del mundo (32\% del total) y, sobre todo, concentra casi el $60 \%$ de las reservas conocidas y explotables con la tecnología actual. Esas cifras justifican por sí solas la importancia geoestratégica de los países de la región, desde Arabia Saudita, Irán, Irak o las petromonarquías del golfo Pérsico, así como la presencia de empresas, bases militares e intervenciones armadas estadounidenses en el área, tanto para asegurar los abastecimientos como para frenar la influencia de potenciales rivales como China. Esa pugna se expandió en las dos últimas décadas a regiones productoras emergentes como el golfo de Guinea, el Sahel o la región del Caspio, aquí en competencia con Rusia. La inestable situación de Estados como Nigeria, Angola, Chad, Sudán del Sur, Kazajstán o Turkmenistán puede verse agravada en el futuro próximo ante las ambiciones desatadas por el control de sus recursos.

Las necesidades de seguridad se extienden también al control de las principales rutas marítimas o terrestres por donde circulan o pueden circular en el futuro esos hidrocarburos. Se identifican así una serie de pasos marítimos por los que transitan a diario varios millones de barriles de crudo procedente del golfo Pérsico en dirección a Occidente y Asia Pacífico, cuyo control resulta vital y cuya amenaza de cierre es una de las claves de las actuales tensiones con el régimen iraní. Los estrechos de Ormuz, Bósforo, Bab el.Mandeb y Malaca, junto al canal de Suez, se ven así flanqueados por un elevado número de bases militares estadounidenses, a las que en los últimos años se suman las emplazadas por China en Pakistán, Birmania, Bangladesh o Sri Lanka, como parte del llamado collar de perlas.

Algo similar ocurre con la protección de las redes de oleoductos y gasoductos terrestres, así como con las arduas negociaciones para dibujar el trazado de esas arterias estratégicas para el abastecimiento de las grandes potencias, que alcanza su mejor reflejo en la región comprendida entre los mares Caspio y Negro (Marcu, 2007). Por un lado, la creciente influencia estadounidense en la región tras el final de la guerra fría y su deseo de evitar el paso de esos recursos por Rusia impulsó la construcción del oleoducto Bakú-Tiflis-Ceyhan, inaugurado en 2005 y reflejo del valor geoestratégico de Azerbayán, Georgia y Turquía en las relaciones de poder que se tejen en el área. Por otro, Rusia basa su recuperación como gran potencia en la abundancia de recursos energéticos $(12 \%$ de la producción mundial de petróleo, $8 \%$ de uranio, $4 \%$ de carbón), que tienen su mejor exponente en el caso del gas natural, del que es primer productor mundial (21\% del total), con unas exportaciones 
dirigidas sobre todo a la Unión Europea. Esa interdependencia se convierte en la base de un complejo equilibrio en el que la UE busca diversificar sus abastecimientos (desde Asia Central o norte de África) y promueve la construcción del gasoducto Nabucco, que desde Azerbayán-Georgia-Turquía atraviesa diversos países balcánicos y alcanza Europa central. Como contrapunto, Rusia define una diplomacia energética en que la empresa Gazprom ofrece precios diferentes a las antiguas repúblicas de la URSS según sean más afines a sus intereses (Bielorrusia, Moldavia) o menos (Ucrania), al tiempo que construye el gasoducto South Stream alternativo al anterior, o el North Stream bajo el Báltico, para llegar a Alemania sin tocar suelo polaco.

Hace una década Klare afirmaba que «porque son valiosos y confieren poder y riqueza, la disputa por los recursos deviene un rasgo cada vez más destacado del panorama mundial» (Klare, 2003: 11). Por su parte, Collier (2007) escribió sobre la maldición de los recursos naturales señalando que en numerosos países su abundancia no contribuyó a promover su desarrollo y sí a convertirlos en objeto de ambiciones que a menudo desembocan en violencia armada. Ambas afirmaciones confirman un significado geopolítico que está lejos de atenuarse con el paso del tiempo.

\subsection{Violencia estructural y violencia armada: las persistentes raíces sociales de los conflictos}

Hace ya tiempo que Galtung definió la existencia de un triángulo de la violencia, diferenciando la ejercida de forma directa sobre las personas de aquella otra que calificó como indirecta, de la que forman parte la violencia estructural, de raíz socioeconómica, y la cultural. También precisó que «la violencia indirecta proviene de la propia estructura social: entre seres humanos, entre conjuntos de seres humanos (sociedades), entre conjuntos de sociedades en el mundo» (Galtung, 2003: 20) y que su permanencia puede desencadenar la violencia armada.

El aumento de las desigualdades sociales - de ingresos, pero también de derechos, oportunidades y, en definitiva, poder - visible en numerosos territorios no es sólo un fenómeno explicable por causas internas a los mismos, sino que también es resultado de la lógica que preside el actual proceso de globalización, basada en una competencia creciente entre desiguales, una progresiva liberalización de los movimientos del capital y un adelgazamiento de las instituciones de protección social. La relación entre esta tendencia y los conflictos armados actuales puede establecerse en una doble dirección: por un lado, la pobreza y la desigualdad son una forma de violencia estructural que a menudo alimenta otras pues, como afirma Serfati (2001: 36), «las condiciones de vida desastrosas de las poblaciones, la desesperación y la miseria constituyen vectores mayores de violencia»; al tiempo, los excluidos o situados en la base de la pirámide social tienen mayor riesgo de ser víctimas directas de esos conflictos ante su evidente vulnerabilidad.

Así pues, un factor importante en la explicación del mapa de los conflictos guarda relación con las condiciones sociales y económicas existentes en los territorios y el desigual acceso a unas condiciones de vida dignas. En tal sentido, cualquier mirada superficial muestra que la mayoría de áreas que padecen enfrentamientos endémicos, o que se han intensificado al compás de la globalización, se localizan en países y regiones que también muestran un bajo índice de desarrollo humano y fuertes contrastes en las condiciones de vida de su población, llegándose incluso al establecimiento de correlaciones estadísticas en ese sentido (Collier, 2007).

La pobreza no conduce necesariamente a la violencia, pero cuando a ella se suman el desempleo, la precariedad, la inequidad y la falta de expectativas, el descontento alimenta 
un ambiente propicio a la insurrección, particularmente entre los jóvenes y no sólo entre los más desfavorecidos, sino también entre las clases medias urbanas. Los negativos efectos de la globalización sobre determinadas actividades tradicionales en numerosas sociedades, el éxodo masivo hacia los suburbios de las megaciudades, junto al frecuente abandono por parte de sus respectivos Estados de servicios elementales para su población, ya sea por insuficiencia de recursos, corrupción o como respuesta a las exigencias de los organismos internacionales para acceder al crédito y asegurar el pago de la deuda, no han hecho sino agravar esa situación.

El diagnóstico que puede extraerse del Informe sobre Desarrollo Humano ofrece una amplia gama de razones para la preocupación. De este modo, aunque el desarrollo humano progresó en las dos últimas décadas y de ello da cuenta el aumento del índice de desarrollo humano desde un promedio de 0,57 en 1990 hasta 0,68 en 2010 para el conjunto del mundo, se trata de una tendencia muy influida por la favorable evolución de algunos grandes países, sobre todo asiáticos, que no puede ignorar la pervivencia o el reforzamiento de importantes diferencias. Así, por ejemplo, la desigualdad en materia de ingresos aumentó, tanto en el plano territorial (entre países, regiones, o áreas urbanas y rurales) como en el social, y «por cada país donde la desigualdad ha disminuido en los últimos veinte a treinta años, aumentó en más de dos» (PNUD, 2010: 81). Si en 1990 se estimaba que los ingresos medios del 5\% más rico de la población mundial eran 50 veces los del $5 \%$ más pobre, hoy se calcula que los superan en 120 veces, al tiempo que concentran una tercera parte de toda la riqueza mundial, proporción similar a la del $80 \%$ con las rentas más bajas.

En ese contexto, la crisis financiera desencadenada en 2008 destruyó al menos 34 millones de empleos en tan sólo dos años y condenó a 65 millones más de personas en el mundo a reducir sus ingresos por debajo de 1,25 dólares diarios, que es la línea oficial de la pobreza extrema. Finalmente, en la actualidad un total de 1.750 millones de personas en los 104 países para los que se dispuso de información viven en situación de pobreza multidimensional, indicador que integra hasta diez dimensiones complementarias y que ofrece una cifra bastante superior a los 1.440 millones de individuos por debajo de 1,25 dólares diarios, con Asia Meridional (844 millones) y África subsahariana (458 millones) muy por encima del resto. Por su parte, el último informe de la Organización Internacional del Trabajo sobre Tendencias Mundiales del Empleo ofrece una estimación oficial de 205 millones de desempleados en el mundo, de los que 78 millones corresponderían a jóvenes menores de 25 años, junto a una cifra de 1.530 millones de trabajadores con empleo vulnerable, asociado a bajos salarios, inestabilidad, condiciones de trabajo deficientes y falta de derechos, que equivale a la mitad del total de efectivos laborales contabilizados (OIT, 2011).

Pero, al mismo tiempo, la pobreza no sólo aumenta la inseguridad económica o laboral, sino también la posibilidad de verse afectado de manera directa por unos conflictos armados que hoy contabilizan entre la población civil más del $80 \%$ de sus víctimas. Puede afirmarse, pues, que «existe una afinidad selectiva entre la desigualdad social y la probabilidad de transformarse en víctima de las catástrofes, ya sean por la mano humana o naturales... Ocupar el extremo inferior en la escala de la desigualdad y pasar a ser víctima colateral de una acción humana o un desastre natural son posiciones que interactúan como los polos opuestos de un imán: tienden a gravitar la una hacia la otra» (Bauman, 2011: 14).

En definitiva, aunque a menudo la apariencia de numerosos conflictos intraestatales se asocia a incompatibilidades de origen étnico, religioso o cultural, mientras que en otros con participación de potencias exteriores es frecuente la referencia a intereses económicos, puede afirmarse que el conflicto social está en la raíz de muchos de ellos. En fechas recientes, las revueltas populares en algunos países árabes como Túnez, Egipto, Libia o 
Siria, que tienen como detonante la reivindicación de libertades políticas frente a regímenes autocráticos y corruptos, tampoco resultan ajenas en su origen al creciente malestar que supone una brecha social cada vez más visible, acentuada por una presión demográfica también en aumento y que encuentra su mejor exponente en los suburbios de las grandes ciudades, donde se gestaron buena parte de esas demandas de cambio.

\subsection{Quiebra del Estado, tráficos ilegales y violencia difusa}

En los últimos veinte años se ha producido una fragmentación del mapa político mundial con la proliferación de Estados soberanos representados en Naciones Unidas, que eran 159 en 1990 y alcanzan los 193 en la actualidad. En paralelo, también se ha incrementado el número de los que «padecen guerras intestinas, epidemias, tráficos sórdidos, corrupción generalizada, delicuescencia de las instituciones, desintegración del entramado social, paro excesivo, absoluta falta de esperanza» (Maalouf, 2009: 21-22). Más allá del debate académico sobre si la denominación de Estados fallidos u otras alternativas (frágiles, débiles, inviables o desesetructurados) resultan más o menos adecuadas, lo que sí resulta indiscutible es que buena parte de la inseguridad creciente que viven, por ejemplo, los países del Sahel, desde Mauritania a Sudán y el Cuerno de África, pasando por algunos de los lugares más pobres del mundo (Mali, Níger, República Centroafricana, Etiopía, Eritrea, Somalia...), hunde sus raíces en este tipo de situaciones, que se extienden a otros muchos lugares, sobre todo en Asia sudoccidental (Taibo, 2006; Lee, 2010).

Se trata, pues, de Estados incapaces de cumplir muchas de las funciones básicas que legitiman su existencia, desde la seguridad de sus ciudadanos y la satisfacción de sus necesidades básicas al control de su territorio y sus fronteras, el impulso del crecimiento económico o el mantenimiento de instituciones políticas estables. En el plano aquí considerado, la incapacidad para imponer su autoridad en todo el territorio se asocia a menudo con la presencia de grupos armados enfrentados al ejército y que llegan a suplantar al propio Estado en ciertas zonas grises ajenas a cualquier legalidad, salvo la impuesta por la fuerza. Esta situación supone mayor riesgo para su población de verse implicada en conflictos violentos, pero también afecta otras dimensiones de la seguridad humana, tales como exposición a destrucciones materiales, desplazamientos masivos o catástrofes humanitarias.

Esa quiebra del Estado genera un ambiente propicio para la proliferación de diversos tipos de tráficos ilegales, tanto de drogas como de personas, armas, minerales estratégicos (diamantes, coltán, casiterita...) o maderas tropicales, que ya existían con anterioridad pero que hoy alimentan una economía criminal con una dimensión antes desconocida, pues estimaciones de Naciones Unidas la sitúan en 1,2 a 3,1 billones de dólares en 2010, lo que equivaldría al 2-5\% del PIB mundial. En ese sentido, resulta discutible vincular el origen de la situación tan sólo a factores internos, pues estos tráficos que financian a numerosos grupos armados y favorecen una violencia difusa en las áreas de producción sólo pueden entenderse a partir de su conexión con redes globales que gestionan el transporte y la distribución de los productos en los mercados internacionales, junto al blanqueo de los capitales generados y su integración en los circuitos de la economía legal, asunto en el que los paraísos fiscales juegan una importante función al preservar la opacidad de tales flujos (ATTAC, 2009) y alimentar ese capitalismo tóxico denunciado por Husson (2008).

Finalmente, tal como recuerda Roudaut (2011: 39), «la inestabilidad llama al crimen y el crimen aumenta la inestabilidad». En ese sentido, una parte importante de los conflictos que desde hace décadas afectan a países tan diversos como Afganistán, la República Democrática del Congo, Sierra Leona, Colombia, México, o los del Triángulo de Oro en el sudeste asiático encuentran aquí una de las razones de su pervivencia. Es bien conocido, 
por ejemplo, el caso de Afganistán, donde los talibanes y otros señores de la guerra obtienen anualmente entre 90 y 160 millones de dólares mediante impuestos que gravan la producción y comercio del opio en las áreas que controlan. Pero a estos ingresos se suman los obtenidos por diferentes grupos armados de Asia Central (Movimiento Islámico de Uzbekistán, Partido Islámico de Turkmenistán...) que controlan ese tramo de la ruta que a través de Rusia - donde pasa al control de otros grupos mafiosos - permite que llegue a Europa una parte del opio o la heroína producidos en ese país.

Tampoco en estos casos tiene sentido buscar una causa única de los conflictos, pero cabe afirmar que si el control de este tipo de tráficos aporta los medios para apoyar otro tipo de causas, en bastantes casos llega a convertirse en sí mismo en una causa. Al mismo tiempo, una visión del conflicto capaz de integrar el espacio de los lugares y el de los flujos puede aportar una lectura compleja y adecuada para avanzar en una comprensión del problema que incluya una dimensión geográfica relevante.

\section{CONSIDERACIONES FINALES}

Un panorama esencialmente interpretativo sobre los rasgos que mejor definen los conflictos armados de nuestra era y los debates abiertos sobre sus principales causas sólo puede finalizar con algunos comentarios adicionales que sitúen esta temática de investigación en su contexto.

El proceso de globalización económica y liberalización de los flujos de mercancías, capitales e información, que experimentó un salto cualitativo tras la desaparición de la Unión Soviética y el final del enfrentamiento bipolar, no ha traído consigo un mundo más seguro y pacífico. Aunque las guerras entre Estados son ahora la excepción y no se atisba en el futuro próximo una conflagración bélica por la hegemonía mundial como las producidas en el siglo XX, se han multiplicado y diversificado los conflictos armados protagonizados por actores de muy distinto signo que ahora se añaden a los ejércitos estatales. La inseguridad global asociada a las acciones terroristas llevadas a cabo por organizaciones que funcionan como redes deslocalizadas se colocó en el primer plano de la atención internacional tras los atentados del 11-S en Estados Unidos, pero el mapa de los conflictos sigue concentrando sus efectos más devastadores en ciertas regiones del planeta.

La perspectiva geográfica puede hacer aportaciones en el análisis de esa distribución de los conflictos y las claves que se encuentran en el pasado y el presente de cada territorio, pero también en la necesidad de situarlos en una perspectiva multiescalar en que interaccionan actores muy diversos. Los sucesivos apartados del artículo han pretendido aportar un estado de la cuestión y proponer la revisión crítica de algunas ideas difundidas en estos años, para suscitar debates que puedan resultar de utilidad en el estudio de conflictos específicos.

En momentos como el actual, en que la sociedad demanda de forma creciente respuestas para hacer frente a los retos de un sistema mundial con graves problemas de gobernanza, la perspectiva geopolítica recobra su significado para interpretar algunos de los procesos en curso. La atención a las relaciones de poder que subyacen a todo tipo de conflictos territoriales y la recuperación de las visiones de conjunto, en una etapa en que la influencia de los procesos estructurales y los actores globales se hace cada vez más visible para entender lo que sucede en nuestro entorno próximo, suponen la otra llamada de atención que el texto ha pretendido fundamentar. 


\section{Bibliografía}

AGIER, M. (2007): «Le gouvernement humanitaire et la politique des réfugiés». Asylon(s). no 2, pp. 1-14. Disponible en http://www.reseau-terra.eu/article671.html.

ATTAC (2009): Les paradis fiscaux, agents de la crise financière. Disponible en http://www.france. attac.org/spip.php?article9551

BAUMAN, Z. (2011): Collateral damage. Social inequalities in a global age. Londres, Polity Press (Traducción española: Daños colaterales. Desigualdades sociales en la era global. Madrid, Fondo de Cultura Económica, 2011).

BECK, U. (2005): «War is peace: on post-national war». Security Dialogue, no 36, pp. 5-26.

BENHAMMOU, F. (2009): «Nourrir l'humanité: une géopolitique de l'alimentation et de l'environnement». Écologie \& Politique, $\mathrm{n}^{\circ}$ 38, pp. 17-32.

COLLIER, P. (2007): The bottom billion. Why the poorest countries are failing and what can be done about it. Oxford, Oxford University Press (Traducción española: El club de la miseria. Qué falla en los países más pobres del mundo. Madrid, Turner, 2008).

DE CASTRO, J. (1951): Geopolitica da fome. Río de Janeiro, Casa do Estudante do Brasil (Traducción española: Geopolítica del hambre. Madrid, Guadarrama, 2 vols., 1972).

EIA (2009): International Energy Outlook 2009. Washington, US Energy Information Administration. Disponible en http://www.eia.doe.gov/oiaf/ieo/ world.html.

FANTINI, E. (2003): »Il futuro dell'acqua tra guerra e mercato». Aggiornamenti Sociali, $\mathrm{n}^{\circ}$ 54, pp. 435-446.

FAO (2011). El estado mundial de la agricultura y la alimentación 2010-2011. Roma, Organización de Naciones Unidas para la Agricultura y la Alimentación.

FOX, J. (2005). «Paradigm lost: Huntington's unfulfilled clash of civilizations prediction into the 21 st century». International Politics, $\mathrm{n}^{\circ} 42$, pp. 428-457.

GALTUNG, J. (1996): Peace by peaceful means. Peace and conflict, development and civilization. International Peace Research Institute, Oslo (Traducción española: Paz por medios pacíficos. Paz y conflicto, desarrollo y civilización. Bilbao, Bakeaz, 2003).

GREGORY, D. (2010). «War and peace». Transactions of the Institute of British Geographers, $\mathrm{n}^{\circ}$ 35, pp. 154-186.

HARBOM, L. y WALLENSTEEN, P. (2005): «Armed conflict and its international dimensions, 1946-2004». Journal of Peace Research, vol. 42, nº 5, pp. 623-635.

HARVEY, D. (2000): Spaces of hope. Universidad de California Press, Berkeley (Traducción española: Espacios de esperanza. Madrid: Akal, 2003).

HOBSBAWM, E. (2007): Globalization, democracy and terrorism. Londres, Abacus (Traducción española: Guerra y paz en el siglo XXI. Barcelona, Crítica, 2009).

HUILLIER, H. (2003): «Pétrole et relations internationales depuis 1945». Questions Internationales, $\mathrm{n}^{\mathrm{o}} 2$, pp. 6-17.

HUNTINGTON, S.P. (1997): The clash of civilizations and the remaking of world order. Nueva York, Simon \& Schuster (Traducción española: El choque de civilizaciones y la reconfiguración del orden mundial. Barcelona, Paidós, 1998).

HUSSON, M. (2008): Un pur capitalisme. Lausana, Éditions Page Deux (Traducción española: Capitalismo puro. Madrid, Ediciones Maia, 2009).

KALDOR, M. (1999): New \& old wars. Organised violence in a global era. Stanford, Stanford University Press (Traducción española: Las nuevas guerras. Violencia organizada en la era global. Barcelona, Tusquets Editores, 2001).

KENNEDY, P. (1987): The rise and fall of the great powers. Londres, Unwin Hyman (Traducción española: Auge y caída de las grandes potencias. Barcelona, Plaza Janés, 1988).

KLARE, M.T. (2001): Resource Wars: the new landscape of global conflict. Nueva York, Henry Holt and Co. (Traducción española: Guerras por los recursos. El futuro escenario del conflicto global. Barcelona, Ediciones Urano, 2003).

LEE, M. (2010): Trafficking and global crime control. Londres, Sage Publications.

LOSANO, M.G. (2011). La geopolitica del Novecento. Dei Grandi Spazi delle dittature alla decolonizzazzione. Milán-Turín, Bruno Mondadori. 
MAALOUF, A. (1998): Les identités meurtrières. Éditions Grasset \& Fasquelle, París (Traducción española: Identidades asesinas. Madrid, Alianza Editorial, 1999).

MAALOUF, A. (2009): Le dérèglement du monde. Quand nos civilisations s'epuisent. París, Éditions Grasset et Fasquelle (Traducción española: El desajuste del mundo. Cuando nuestras civilizaciones se agotan. Madrid, Alianza Editorial, 2009).

MARCU, S. (2007): El mar Negro. Geopolítica de una región encrucijada de caminos. Valladolid, Universidad de Valladolid.

MEGORAN, N. (2011): «War and peace? An agenda for peace research and practice in geography». Political Geography, vol. 30, nº 4, pp. 178-189.

MÉNDEZ, R. (2011): El nuevo mapa geopolítico del mundo. Valencia, Tirant lo Blanch.

NAYLOR, R.T. (2005): Wages of crime: black markets, illegal finance and the underworld economy. Ithaca, Cornell University Press.

NOGUÉ, J. y VICENTE, J. (2001): Geopolítica, identidad y globalización. Barcelona, Ariel.

OIT (2011): Tendencias mundiales del empleo de 2011. El desafío de la recuperación del empleo. Ginebra, Oficina Internacional del Trabajo.

PNUD (2010): Informe sobre Desarrollo Humano 2010. La verdadera riqueza de las naciones: caminos al desarrollo humano. Nueva York y Madrid, PNUD y Ediciones Mundi- Prensa.

PRAT CARVAJAL, E. edit. (2010): Las raíces históricas de los conflictos armados actuales. Valencia, Publicaciones Universidad de Valencia.

ROMERO, J. y NOGUÉ, J. (2007): «Globalización y nuevo (des)orden mundial». En J. Romero dir. Geografía humana. Procesos, riesgos e incertidumbres en un mundo globalizado. Barcelona, Ariel, $2^{\mathrm{a}}$ edición, pp. 105-172.

ROUDAUT, M.R. (2011): «Géopolitique de l'illicite. La nouvelle main invisible». Diplomatie, n ${ }^{\circ}$ 50, pp. 38-46.

RUSSET, B. M., O’NEAL J. R., y COX, M. (2000): «Clash of civilizations, or realism and liberalism déjà vu? Some evidence». Journal of Peace Research, $\mathrm{n}^{\circ}$ 37, pp. 583-608.

SERFATI, C. (2001): La mondialisation armée. Le déséquilibre de la terreur. París, Les Éditions Textuel.

SHIVA, V. (2002): Water wars: privatization, pollution and profit. Cambridge MA, South End Press.

SINGER, P.W. (2003): Corporate warriors. The rise of the privatized military industry. Nueva York, Cornell University Press.

STÉPHANE, R. y YANN, R. (2011): Géographie des conflits armés et des violences politiques. París, Ellipses.

TAIBO, C. (2006): «La descartografía del mundo. Estados fallidos y conflictos olvidados». En J. Nogué y J. Romero (eds.). Las otras geografías. Valencia, Tirant lo Blanch, pp. 81-96.

WORLD ECONOMIC FORUM (2011): Global risks 2011. Ginebra, World Economic Forum. 